\title{
Calcium Homeostasis Comparison in Thermal Burn Patients-Early Tangential Excision and Grafting versus Conservative Management
}

\author{
Sonika Jha ${ }^{1}$ Parul Goyal ${ }^{2}$ Sameek Bhattacharya ${ }^{1}$ \\ ${ }^{1}$ Department of Burns, Plastic and Maxillofacial Surgery, Dr. Ram \\ Manohar Lohia Hospital and Atal Bihari Vajpayee Institute of \\ Medical Sciences (ABVIMS), New Delhi, India \\ ${ }^{2}$ Department of Biochemistry, Dr. Ram Manohar Lohia Hospital and \\ Atal Bihari Vajpayee Institute of Medical Sciences, New Delhi, India \\ Indian J Plast Surg:2020;53:381-386
}

\author{
Shilpi Baranwal ${ }^{1}$
}

\begin{abstract}
Introduction With the advent of better burn wound management protocols, early excision and grafting, increased number of burns patients are surviving and entering the struggle of prolonged rehabilitation. Calcium homeostasis and its influence on bone mineralization plays an important role, but it is adversely influenced by the proinflammatory state in burns, leading to hypocalcemia and paradoxical hypercalciuria which, in turn, leads to excessive bony resorption and pathological fractures. The role of early excision in the overall metabolism of calcium is being investigated in the study.

Method This study was undertaken in a tertiary level government-run hospital from February 2018 to August 2019. A total of 28 patients with second degree thermal burns were included. For all patients, fasting serum parathormone levels along with various serum electrolytes like $\mathrm{Ca}^{2+}, \mathrm{Mg}^{2+}, \mathrm{PO}_{4}{ }^{3-}$ and urinary calcium levels were serially measured from day of admission to 2 months. The first group of 14 patients (Group A) underwent early tangential excision and skin grafting, whereas another 14 patients (Group B) underwent conservative management. All categorical variables were analyzed with the help of Chi square test. A $p$ value of $<0.05$ was considered statistically significant.

Keywords

- homeostasis

- hypercalciuria

Result There was a statistically significant improvement in serum parathormone and other electrolytes' levels in the tangential excision group. Similarly, urinary excretion of calcium also showed favorable results in the group.

- hypocalcemia

- parathormone

- tangential excision in maintaining serum parathormone and calcium levels, leading to prevention of hypercalciuria and optimization of other factors affecting calcium homeostasis.
\end{abstract}

\section{Introduction}

Thermal burns continue to be a public health menace. In India, around 7 million people suffer from burn injuries

published online

December 30, 2020
DOI https://doi.org/

$10.1055 / \mathrm{s}-0040-1716474$

ISSN 0970-0358. each year, with 1.4 lakh deaths recorded and 2.4 lakh people afflicted with disability. ${ }^{1,2}$

Care of thermal burns has improved with the advent of evidence-based practice and better wound care. As more
C2020. Association of Plastic Surgeons of India.

This is an open access article published by Thieme under the terms of the Creative Commons Attribution-NonDerivative-NonCommercial-License, permitting copying and reproduction so long as the original work is given appropriate credit. Contents may not be used for commercial purposes, or adapted, remixed, transformed or built upon. (https://creativecommons.org/licenses/by-nc-nd/4.0/). Thieme Medical and Scientific Publishers Pvt. Ltd. A-12, 2nd Floor, Sector 2, Noida-201301 UP, India 
patients survive the initial insult of thermal burns, the longterm metabolic consequences of burns are being brought to light. One of these is the derangement of calcium metabolism that occurs in burn patients. ${ }^{2}$

In a healthy person, calcium metabolism comes under the modifying influence of parathormone, with calcitonin playing an insignificant role in humans. Parathormone is, in turn, under the negative feedback of circulating serum calcium. There is evidence of disordered calcium homeostasis following burns, ${ }^{2,3}$ which include upregulation of calcium sensing $\mathrm{G}$ protein coupled receptors on the chief cells of parathyroid gland. In the physiological state, low-serum calcium levels are responsible for sensitization of parathormone release. But this upregulation of receptors sensitizes the parathyroid gland to even the low levels of free serum calcium, thus setting the cutoff point of serum parathormone to a new nadir. ${ }^{3,4}$

The magnesium ion goes hand in glove with calcium metabolism $^{5}$ and is essential for proper function of most energy systems. Its depletion is characterized by neuromuscular and central nervous hyperactivity. ${ }^{6}$ The diagnosis of magnesium deficiency depends on the awareness of hypomagnesemia and clinical recognition of the symptoms till laboratory confirmation is available. Magnesium deficiency is correctable by proper magnesium therapy through oral and parental route in appropriate doses. ${ }^{7}$

Burn injury is a state of net calcium, magnesium and phosphate loss. ${ }^{6,7}$ This is evident from calciuria, despite low-circulating serum calcium, serum magnesium, serum phosphate, serum parathormone and serum vitamin D. ${ }^{7,8}$

Unlike calcium, phosphorus absorption goes unabated across a healthy gut irrespective of serum levels. Thus, it comes down to the ingenuity of the Henle's loop and distal convoluted tubule (DCT) wherein phosphorus regulation occurs by virtue of being linked to calcium and ergo under the influence of parathyroid, which increases phosphorus excretion at the cost of calcium reabsorption. ${ }^{6,7}$

This study aims to identify whether early wound closure in the burnt state corrects the deranged parathyroid function, which is attributable to the proinflammatory state, thereby optimizing overall calcium homeostasis.

\section{Materials and Methods}

\section{Study Design}

A prospective observational case control study was performed in a government-run, tertiary-level burns center cum teaching hospital. A study cohort was formed composed of 28 burn patients admitted to the Burns Unit between July 2017 to December 2018 burns.

Inclusion criteria: Patients in the age group between 16 to 60 years with thermal burns of up to second degree depth and involving 20 to 40 percent total burn surface area (TBSA) were included in this study.

Exclusion criteria: Patients with associated systemic comorbidities like acute respiratory distress syndrome, head injury, abdominal or chest injury, inhalational component of burn, uncontrolled diabetes mellitus, pre-existing chronic kidney disease or new onset renal failure, chronic liver disease, and nonthermal burns were excluded from this study.

\section{Allocation of Study Groups}

The patients fulfilling the inclusion criteria were randomly allocated in either group, with Group A being the tangential excision group and Group B being the conservative management group. The randomization was done by random group allocation software. Each group was a cohort of 14 patients.

\section{Tangential Excision Group (Group A)}

Humby's knife was used for tangential excision and grafting. All white, pinprick insensate wounds were considered for grafting between 3 to 7 days of burns with prior adrenaline solution infiltration. Excision was done till punctuate bleeding occurred and meticulous hemostasis was achieved with adrenaline solution (1 in 1 lac dilution) soaked gauze, bipolar cautery and compression as required by the operating surgeon.

Tourniquet use: Limb exsanguinations and tourniquet application was done prior to excision. The capillary refill was constantly measured in the pulp of digits.

The wound was covered with thin split-thickness skin graft, and compressive dressing was done using mupirocin ointment-soaked paraffin gauze and dry gauze. The rest of the burn area was dressed with long-acting nanocrystalline silver dressing.

Postoperative dressing: Wound examined at 24 hours, replacing the primary dressing. First dressing was done on day 3 and subsequently every alternate day. Dressing was done with paraffin tulle, mupirocin ointment, saline-soaked gauze and appropriate splinting.

\section{Conservative Management Group (Group B)}

Regular dressing with nanocrystalline silver-based dressing, as provided by the hospital surgical store. Splinting of appropriate part done, according to pattern of burns. Also, supportive treatment in the form of antibiotics like third generation cephalosporins, nonopioid analgesics and IV fluids constitute treatment, which was common in both groups. Dressing was done every 3 to 5 days, as per department's protocol. Exceptions to this rule were: a) soiled dressing, b) unexplained fever or pain, c) performing debridement/ collecting wound swab of selective areas.

Dietary supplementation: All patients in either group having similar TBSA \% burns received similar diet from the hospital dietary department and were routinely supplemented with oral calcium. All received daily supplementation with $500 \mathrm{mg}$ calcium and 250 international units of vitamin D3 for the first 7 days, following which supplementation was done only when indicated.

Blood transfusion: Blood transfusion was done when hemoglobin levels $<8 \mathrm{mg} / \mathrm{dl}$ or per operatively during excessive blood loss. None required $>$ or equal to 2 units within 24 hours, thereby affecting serum calcium levels. 
Mobilization: All patients underwent daily in bed physiotherapy to mobilize all major joints. Assisted ambulation was started as soon as the general condition and wound status allowed.

\section{Method}

Biochemical analysis

1) Fasting sample for serum calcium, magnesium and phosphorus studied every third day, starting from first sample on day of admission to burn ward till 15th day and then at 1 month and 2 months, respectively.

2) Fasting sample for serum parathormone and 24-hour urine sample for urinary calcium collected every 10th day of in-hospital stay, starting from first sample at day of admission (before starting supplementation) till 1month and then at 2 months, respectively.

Parenteral supplementation: If a patient was symptomatic for hypocalcemia or routine serum calcium levels were $<7.0 \mathrm{mmol} / \mathrm{dl}$, (after correction), additional supplementation with $10 \%$ calcium gluconate intravenous was given. Total calcium levels were calculated for observation. The serum calcium was corrected to serum albumin, using the following formula:

- Corrected calcium $=$ serum calcium $(\mathrm{mg} / \mathrm{dL})+0.8 \times($ normal albuminemia $[\mathrm{g} / \mathrm{dL}]$-patient albuminemia $[\mathrm{g} / \mathrm{dL}]$ ).

For serum phosphorus and serum magnesium, no regular supplementation was done unless indicated.

All biochemical parameters were analyzed as follows:

- Serum Ca, Mg, P and urinary calcium analyzed on fully automated clinical chemistry analyzer.

- Serum levels parathormone estimated on chemiluminiscence Immuno assay (CLIA) system.

\section{Statistical Analysis}

The data was entered in MS Excel spreadsheet and analysis was done using Statistical Package for Social Sciences (SPSS) version 22.0. Normality of the data was checked with the help of Kolmogorov-Smirnov and Shapiro-Wilk test. All categorical variables were analyzed with the help of Chi square test. A $p$ value of $<0.05$ was considered statistically significant.

\section{Results (-Table 1)}

The mean age of patients in Group A and Group B was 30.53 and 31.85 years, respectively. The most common age group in both Group A and Group B group was 26 to 35 years, and it constituted 50 percent of patients in Group A and 57.2 percent of Group B. The average burn surface area under treatment in Group A was 35.92 percent and in Group B group was slightly higher at 37.14 percent. However, difference was not statistically significant with a $p$ value of 0.791 .

Blood transfusion was required in three patients of the tangential excision group, whereas only two patients in conservative management underwent blood transfusion. The average day for tangential excision and grafting was 4 th postburns day (-Table 2, - Fig. 1).

There was a significant improvement in serum calcium, magnesium and phosphorous levels in the tangential excision group. For serum calcium levels, $p$ value became statistically significant on day 15 and at first and second month of follow-up.

The serum magnesium improved in the tangential excision group compared with the conservatively managed group, which was statistically significant at day 15 of in-patient stay and at 1 st and at 2 nd month of follow-up.

Serum phosphorus levels in the tangential excision group improved on day 12,15 of admission and at 1 st month and 2nd month and were statistically significant ( - Table 3 ).

The mean serum parathormone in Group B was significantly higher in Group A. It remained persistently high during admission and entire follow-up, which correlated with increase calcium loss in Group A at the end of follow-up period (-Table 4).

The 24-hour urinary calcium levels were remarkably low in tangential excision group (Group A) as compared with the nonoperative group. This corroborated with the finding of low-parathormone levels, which were also found in Group A (-Fig. 2).

However, no significant difference was found in the vitamin D levels when the same was recorded at 0, 10, 20 days, and 1 month and 2 months after admission.

On correlation and regression analysis of serum calcium with serum vitamin D and serum parathormone in both groups, a statistically significant correlation was found with $p$ value 0.049 (Group A) and 0.004 (Group B).

\section{Discussion}

The management of patients of thermal burns is aimed not only at addressing the burn wound but also the systemic and metabolic state that ensues with thermal burns.

As resuscitation and monitoring improve and become standardized, more patients survive the initial insult of burn, albeit to face the long-term metabolic consequences pertaining to calcium metabolism.

Table 1 Age and gender distribution of burns patients in both groups along with the average TBSA \%

\begin{tabular}{|l|l|l|l|l|l|l|}
\hline \multirow{2}{*}{ Age group } & \multicolumn{3}{|c|}{ Group A } & \multicolumn{2}{c|}{ Group B } \\
\cline { 2 - 7 } & Males & Female & Average \%TBSA & Male & Female & Average TBSA \% \\
\hline $16-25$ years & 03 & 01 & $39.23 \%$ & 03 & 00 & $36.67 \%$ \\
\hline $26-35$ years & 05 & 02 & $39.68 \%$ & 05 & 03 & $36.38 \%$ \\
\hline$>35$ years & 01 & 02 & $28.67 \%$ & 01 & 02 & $39.27 \%$ \\
\hline
\end{tabular}

Abbreviations: TBSA: total burn surface area. 
Table 2 Comparison of serum calcium, magnesium and phosphorus levels over time

\begin{tabular}{|l|l|l|l|l|l|l|l|l|l|}
\hline \multicolumn{8}{|c|}{ Comparative analysis of various serum electrolytes for calcium homeostasis } \\
\hline \multirow{2}{*}{ S. Ca } & Group A & 7.2286 & 7.3714 & 7.5615 & 7.7846 & 7.7769 & 8.0385 & 8.1385 & 8.3923 \\
\cline { 2 - 11 } & Group B & 7.1643 & 7.3143 & 7.3929 & 7.4286 & 7.5143 & 7.6286 & 7.5714 & 7.75 \\
\hline S. Mg & Group A & 1.5357 & 1.6615 & 1.7769 & 1.8846 & 2.0077 & 2.1615 & 2.3231 & 2.4692 \\
\cline { 2 - 12 } & Group B & 1.55 & 1.6571 & 1.7429 & 1.8214 & 1.9286 & 1.9357 & 1.9429 & 2.0429 \\
\hline S. Ph & Group A & 2.9786 & 3.0786 & 3.2846 & 3.3615 & 3.5385 & 3.5923 & 3.9077 & 4.1077 \\
\cline { 2 - 11 } & Group B & 2.7857 & 2.8286 & 2.9214 & 2.9643 & 3.0143 & 3.0286 & 3.0214 & 3.0824 \\
\hline
\end{tabular}

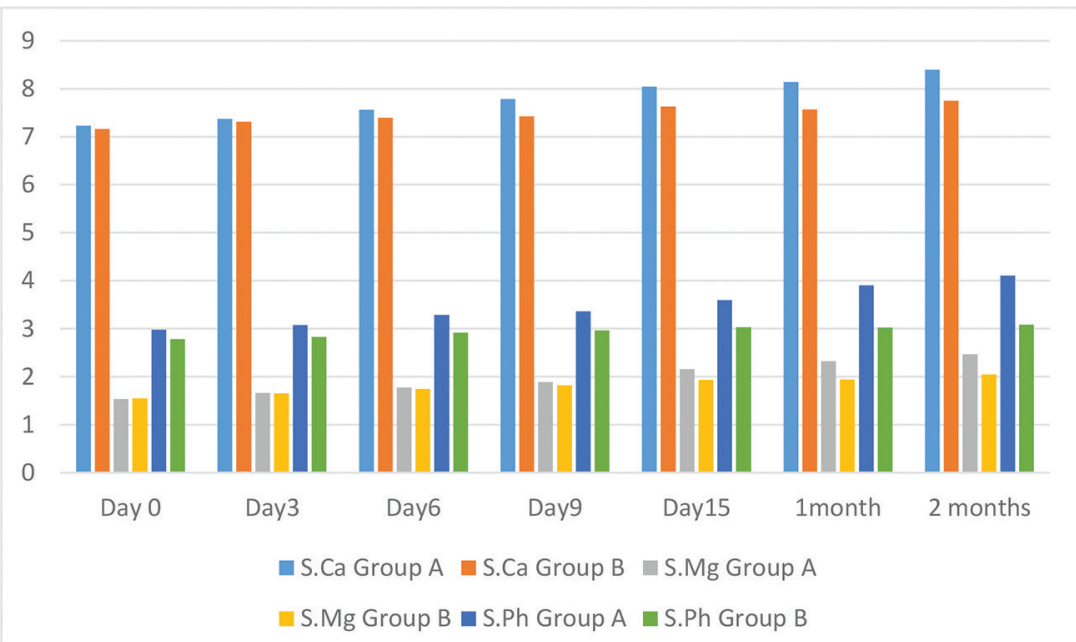

Fig. 1 Comparative analysis of serum electrolyte levels for calcium homeostasis in both groups.

Table 3 Comparison of parathormone levels in both groups

\begin{tabular}{|c|c|c|c|c|c|}
\hline & Groups & Mean & SD & $p$ value & Significance \\
\hline \multirow[t]{2}{*}{ PTH-0 } & Group A & 30.0071 & 7.8633 & \multirow[t]{2}{*}{$<0.001$} & \multirow[t]{2}{*}{$\mathrm{HS}$} \\
\hline & Group B & 49.4286 & 12.2302 & & \\
\hline \multirow[t]{2}{*}{ PTH-10 } & Group A & 30.1154 & 6.66894 & \multirow[t]{2}{*}{$<0.001$} & \multirow[t]{2}{*}{ HS } \\
\hline & Group B & 50.3357 & 9.75607 & & \\
\hline \multirow[t]{2}{*}{ PTH-20 } & Group A & 30.0727 & 6.28762 & \multirow[t]{2}{*}{$<0.001$} & \multirow[t]{2}{*}{$\mathrm{HS}$} \\
\hline & Group B & 49.7286 & 8.99131 & & \\
\hline \multirow[t]{2}{*}{ PTH-1m } & Group A & 26.9462 & 5.78858 & \multirow[t]{2}{*}{$<0.001$} & \multirow[t]{2}{*}{$\mathrm{HS}$} \\
\hline & Group B & 47.95 & 8.02244 & & \\
\hline \multirow[t]{2}{*}{ PTH-2m } & Group A & 25.7762 & 5.70454 & \multirow[t]{2}{*}{$<0.001$} & \multirow[t]{2}{*}{ HS } \\
\hline & Group B & 46.45 & 7.8935 & & \\
\hline
\end{tabular}

In a study conducted by Klein et $\mathrm{al}^{9}$ titled, "Where has all the Calcium gone," they have shown that despite adequate supplementation, children with burns continue to lose supraphysiological amounts of calcium through urine even in a state of low-serum calcium, which continues up to 6 months postburn. In another study by Klein et al, this calcium loss was linked to a proinflammatory state generated by the raw burn wound. ${ }^{10}$ They suggested that immobilization and endogenous corticosteroid production was responsible for the same. There is acute stimulation by proinflammatory cytokines of existing osteoblasts and osteoclasts, leading to both bone resorption and brittle bone formation. Adynamic bone, ${ }^{10}$ then, would not be conducive to mineralization and will further delay early rehabilitation and increase risk of osteoporosis in burn patients. ${ }^{11}$

The link between increased proinflammatory cytokines and an increased synthesis of the calcium sensing receptor 
Table 4 Trend of 24-hour urinary calcium levels in both the groups

\begin{tabular}{|c|c|c|c|c|c|}
\hline & Groups & Mean & SD & $p$ value & Significance \\
\hline \multirow[t]{2}{*}{ UCa-0 } & Group A & 226.23 & 5.18256 & \multirow[t]{2}{*}{$<0.001$} & \multirow[t]{2}{*}{ HS } \\
\hline & Group B & 242.79 & 10.72867 & & \\
\hline \multirow[t]{2}{*}{ UCa-10 } & Group A & 198.08 & 6.37000 & \multirow[t]{2}{*}{$<0.001$} & \multirow[t]{2}{*}{$\mathrm{HS}$} \\
\hline & Group B & 233.43 & 11.34572 & & \\
\hline \multirow[t]{2}{*}{ UCa-20 } & Group A & 172.55 & 11.80986 & \multirow[t]{2}{*}{$<0.001$} & \multirow[t]{2}{*}{$\mathrm{HS}$} \\
\hline & Group B & 226.93 & 11.35080 & & \\
\hline \multirow[t]{2}{*}{ UCa-1m } & Group A & 138.46 & 17.96114 & \multirow[t]{2}{*}{$<0.001$} & \multirow[t]{2}{*}{ HS } \\
\hline & Group B & 226.86 & 13.81113 & & \\
\hline \multirow[t]{2}{*}{ UCa-2m } & Group A & 103.15 & 15.86845 & \multirow[t]{2}{*}{$<0.001$} & \multirow[t]{2}{*}{$\mathrm{HS}$} \\
\hline & Group B & 219.57 & 17.80110 & & \\
\hline
\end{tabular}

\section{$300 \quad$ Urinary Calcium excretion}

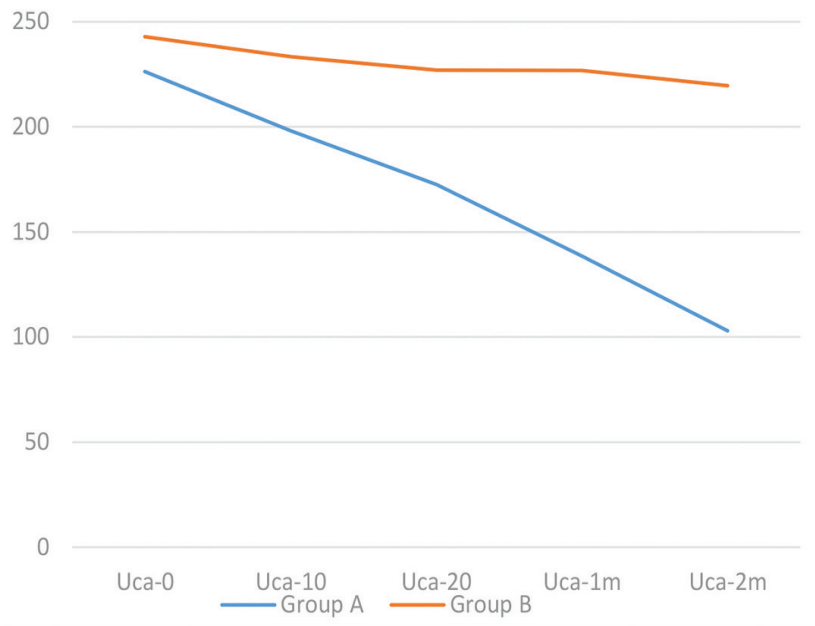

Fig. 2 Trend of 24-hour urinary calcium levels declining in tangential excisiongroup over time..

on the chief cells of parathyroid was suggested by Murphy et $a l,{ }^{12}$ opining that it is this state that leads to deranged intestinal absorption and increased urinary calcium loss. They established that tangential excision and prompt cover with split-thickness skin graft successfully decreased the circulating levels of proinflammatory mediators. Another study by Norbury et $\mathrm{al}^{7}$ supported the role of excisional surgery and grafting with decreasing cortisol levels.

This study also shows a positive effect of early excision and grafting on the disordered calcium levels in burns. The mean serum calcium on admission was $7.2+/-0.4$ $\mathrm{mg} / \mathrm{dl}$ in the tangential excision group and 7.1+/-0.4 mg/ $\mathrm{dl}$ in the conservatively managed group. The final corrected calcium at the end of 2-month follow-up was $8.3+/-0.3 \mathrm{mg} / \mathrm{dl}$ in the tangential excision group and $7.7+/-0.4$ $\mathrm{mg} / \mathrm{dl}$ in the conservatively managed group and found to have significant improvement. A significant improvement was also shown in the urinary 24-hour calcium which was high on day zero. The mean excretion in Group A was
$226.2+/-5.1 \mathrm{mg} /$ day tapered to103.15+/-5.18mg/day over a span of 8 weeks, whereas in Group B, it hardly changed from $242.7+/-10.7 \mathrm{mg} /$ day to $219.5+/-17.8 \mathrm{mg} /$ day.

In an observational study by Berger et al, ${ }^{13}$ patients with 20 to $55 \%$ burns were included and the authors claimed that serum phosphate levels, which were normal on day 0 , continued to decrease till day 5. In patients with lesser surface of burns, the phosphate levels normalized by day 20. In patients with moderate and higher percentage burns, the phosphate level continued to be low up to 3 months follow-up. It was found that almost one third of the loss of phosphate was accounted for by exudative loss and the rest by increased urinary losses.

In our study, we found that that mean serum phosphate levels were low on admission compared with the reference value of 3 to $4.5 \mathrm{mg} / \mathrm{dl}$ in both groups of patients. The mean serum phosphate levels normalized in the tangential excision group by day $6(3.2+/-0.6 \mathrm{mg} / \mathrm{dl})$, whereas it normalized in the conservatively managed group by day $12(3.01+/-0.5 \mathrm{mg} / \mathrm{dl})$. 
In the study by Berger et $a l,{ }^{13}$ mean magnesium remained low for patients who had burn surface areas more than 30 percent TBSA and the hypomagnesemia persisted until the second week. None of these underwent excision and grafting. In our study, the reference level of serum magnesium was taken to be $1.7-2.2 \mathrm{mg} / \mathrm{dl}$. In both tangential excision and conservative management group, the serum magnesium was in the normal range on day $6(1.74+/-0.1 \mathrm{mg} / \mathrm{dl}$ in conservatively managed group and $1.76+/-0.1 \mathrm{mg} / \mathrm{dl}$ in tangential excision group).

Thus, this study supports that a continuing proinflammatory state in burns adversely affects calcium homeostasis, leading to a state of prolonged hypocalcemia and paradoxical hypercalciuria. There is a significant improvement in serum parathormone levels and urinary calcium levels in burns patients undergoing tangential excision as compared with nonoperative group. The serum levels of calcium, magnesium and phosphorus are more likely to remain within physiological limits in patients undergoing early tangential excision.

\section{Conclusion}

Thus, it can be concluded that tangential excision and grafting plays an important role not only in the early burn wound healing but also in maintaining serum parathormone levels, thereby leading to near normal serum calcium levels, prevention of hypercalciuria, and optimization of various electrolytes responsible for calcium homeostasis in burns patients.

\section{Author Disclosures}

There are no conflicts of interest.

\section{References}

1 National Health Portal of India. Available at: https://www.nhp. gov.in/disease/skin/burns. Accessed August 24, 2020

2 Rao S. Nutritional status of the Indian population. J Biosci 2001;26(Suppl):481-489
3 Klein GL. Burn-induced bone loss: importance, mechanisms, and management. J Burns Wounds 2006;5:e5

4 Nielsen PK, Rasmussen AK, Butters R, et al. Inhibition of PTH secretion by interleukin-1 beta in bovine parathyroid glands in vitro is associated with an up-regulation of the calcium-sensing receptor mRNA. Biochem Biophys Res Commun 1997;238(3):880-885

5 Toribio RE, Kohn CW, Capen CC, Rosol TJ. Parathyroid hormone (PTH) secretion, PTH mRNA and calcium-sensing receptor mRNA expression in equine parathyroid cells, and effects of interleukin (IL)-1, IL-6, and tumor necrosis factor-alpha on equine parathyroid cell function. J Mol Endocrinol 2003;31(3):609-620

6 Canaff L, Zhou X, Hendy GN. The proinflammatory cytokine, interleukin-6, up-regulates calcium-sensing receptor gene transcription via Stat1/3 and Sp1/3. J Biol Chem 2008;283(20):13586-13600

7 Castana O, Rempelos G, Faflia C, et al Hypophosphatemia in burns. Annals of Burns and Fire Disasters 2009;22(2):56-9-1

8 Norbury WB, Herndon DN, Branski LK, Chinkes DL, Jeschke MG. Urinary cortisol and catecholamine excretion after burn injury in children. J Clin Endocrinol Metab 2008;93(4):1270-1275

9 Jackson DM, Stone PA. Tangential excision and grafting of burns. The method, and a report of 50 consecutive cases. $\mathrm{Br} \mathrm{J}$ Plast Surg 1972;25(4):416-426

10 Klein GL. Burns: where has all the calcium (and vitamin D) gone? Adv Nutr 2011;2(6):457-462

11 Klein GL, Herndon DN, Rutan TC, et al. Bone disease in burn patients. J Bone Miner Res 1993;8(3):337-345

12 Murphy S, Khaw KT, Prentice A, Compston JE. Relationships between parathyroid hormone, 25-hydroxyvitamin D, and bone mineral density in elderly men. Age Ageing 1993;22(3):198-204

13 Berger MM, Rothen C, Cavadini C, Chiolero RL. Exudative mineral losses after serious burns: a clue to the alterations of magnesium and phosphate metabolism. Am J Clin Nutr 1997;65(5):1473-1481

Calcium Homeostasis Comparison in Thermal Burn Patients Jha et al. 